\title{
Supervisão de Estágio: uma experiência em rede
}

\author{
Karla M. Da Rocha ${ }^{1}$, Ilse Abegg ${ }^{1}$, Eliana Rela ${ }^{2}$ \\ ${ }^{1}$ Centro de Educação, Departamento de Metodologia do Ensino - Universidade Federal \\ de Santa Maria (UFSM) \\ Caixa Postal 15.064 - 97.110-900 - Santa Maria - RS - Brazil \\ ${ }^{2}$ Curso de Licenciatura em História - Universidade de Caxias do Sul (UCS). Rua Padre \\ Carmine Fasulo 236, Caxias do Sul - RS - Brasil \\ Karlarocha@terra.com.br, ilse.abegg@ufsm.br, erela@ucs.br
}

\begin{abstract}
This paper discusses the use of Web-based Educational Technologies, specially the Wiki activity tool in Moodle, on the subject of Supervised Teacher Training of the Special Undergraduate Program of Teachers' Education for Professional and Technological Education. The posts made by twenty nine students and their advisor were analyzed with regards to their teaching lessons and their implementation. The posts enabled a discussion on the Wiki space fostering categories of indicative elements for the supervision for future training by means of conversation networks. The possibility of follow-up, guiding, evaluations and learning became effectively a period of constructing experiences, beyond the academic space.
\end{abstract}

Resumo. Este artigo aborda a utilização das Tecnologias Educacionais em Rede, especialmente o recurso Wiki, na disciplina de Supervisão de Estágio em um Programa Especial de Graduação de Formação de Professores para a Educação Profissional e Tecnológica. Analisou-se os registros feitos por vinte e nove estudantes e o respectivo orientador, referentes aos planos de aula e sua implementação. As postagens geraram reflexões no espaço Wiki, proporcionando categorias de elementos indicadores para a supervisão dos futuros estágios, na forma de rede de conversação. A possibilidade de acompanhamentos, orientações, avaliações e aprendizagens tornou-se efetivamente um período de construção de experiências, além do espaço acadêmico.

\section{Introdução}

No atual momento do processo de formação de professores, nos cursos de licenciatura, uma significativa atenção tem sido dada as propostas de professores reflexivos. Essa proposta, aceita com simpatia por boa parte dos educadores, parte do trabalho de Shön (1992), que propõe que o pensamento reflexivo do professor(a), no enfrentamento das situações divergentes da prática, se desenvolve na competência de refletir sobre a ação, criando uma nova realidade, experimentando, corrigindo e inventando, através do diálogo que estabelece com essa mesma realidade. A reflexão é, portanto, base para o desenvolvimento do profissional e, em se constituindo numa espiral formativa, retorna a reflexão sobre a reflexão na ação (SILVA, 2002). O que nos permite pensar na valorização da prática profissional como momento de construção de conhecimento por meio da reflexão, análise e problematização dessa prática e a consideração do conhecimento tácito, presente nas soluções que os profissionais encontram na ação docente. Através da prática refletida, é possível responder com situações novas às 
situações de incerteza e indefinição que transitam os caminhos da profissão docente (RELA et. al., 2006).

A atual sociedade pode ser concebida como complexa, ambígua na compreensão e conceituação de valores, repleta de evidências contraditórias e de difícil conciliação (MORIN, 2005). Em nosso país, as políticas públicas têm orientado as modificações curriculares, às propostas de eixos articuladores como pressupostos, os quais possuem função de tecer as informações no conjunto em que estão inseridas.

$\mathrm{Na}$ perspectiva de atender as Diretrizes Nacionais (CNE/CP, 2002), os colegiados dos cursos de licenciaturas debatem concepções e estratégias capazes de articular currículos acadêmicos potencializadores na formação de professores levando em consideração as dimensões teóricas e práticas como fundamento da ação pedagógica. Ação pedagógica que deve contemplar, no mínimo 300 horas de estágio supervisionado de ensino, vivenciadas ao longo do curso, como forma de inserção do estudante na prática da atividade docente e no convívio com o ambiente da escola, compartilhando experiências e projetos educativos.

Segundo Pimenta e Lima (2010), o estágio curricular supervisionado tem a finalidade de integrar o processo de formação do aluno, futuro profissional, de modo a considerar o campo de atuação como objeto de análise, de investigação e de interpretação crítica, a partir dos nexos com as disciplinas do curso. Por ser um campo de conhecimento, volta-se a uma visão ampla, em que um processo didáticopedagógico, intencional, possibilita a formação crítica do educador (Professor) a partir da articulação teoria-prática, por meio de intervenções contextualizadas de caráter emancipatório. Nesse sentido, a intervenção dos atores da atividade de estágio deve estar caracterizada por um tempo de formação, que deve ocorrer no mundo real do trabalho, sendo um componente curricular que é orientado por um docente. Este, atua no sentido de considerar o estágio como um momento de ação e reflexão, ou seja, um eixo articulador do curso.

Com base nesses pressupostos e reflexões procurou-se desenvolver um estudo, de natureza qualitativa, envolvendo a análise do conteúdo das postagens e orientações referente aos planos de aula e sua implementação, no Wiki, de uma disciplina presencial. Acredita-se que a construção do conhecimento e mudanças de conduta, a partir das reflexões das próprias ações, em um espaço tecnológico, possam contribuir para a orientação do estágio supervisionado, na medida em que o recurso pode proporcionar um espaço de conversa, interação e análise da prática do futuro docente. Procurou-se, a partir deste enfoque, estruturar o texto em três etapas, que, apesar de estarem hierarquicamente listadas, se entrelaçam em todos os momentos desta reflexão sobre a reflexão na ação. Portanto, buscou-se:

1 - Abordar a ferramenta wiki do moodle, como um recurso tecnológico possível de ser utilizado nas atividades de orientação de estágio supervisionado de ensino, nos cursos de licenciatura, no caso, o Programa Especial de Graduação de Formação de Professores para a Educação Profissional e Tecnológica;

2 - Analisar as possibilidades da ferramenta wiki, como espaço de diálogo, interação e reflexão do aluno estagiário e seu orientador; 
3 - Analisar as contribuições desses diálogos, interações, e reflexões, mediadas pela ferramenta wiki, para a formação do professor reflexivo, da Educação Profissional.

\title{
2. Wiki: um espaço para ação-reflexão-ação em rede
}

\author{
Como animais linguajantes, existimos na linguagem, mas como seres \\ humanos existimos (trazemos nós mesmos à mão em nossas distinções) no \\ fluir de nossas conversações, e todas as nossas atividades acontecem como \\ diferentes espécies de conversação (VIEIRA, 2004).
}

Segundo o autor, é na conversação que ocorre a coordenação consensual de ações. Para Maturana (2002), coordenações consensuais são as interação na linguagem, ou seja, a linguagem é considerada como um espaço construído por ações que se tornam comuns e, por isso consensuais. Já a palavra "conversar", segundo Maturana (2002), vem da união de duas raízes latinas: cum, que quer dizer "com", e versare que quer dizer "dar voltas com" o outro. Então, ao conversarmos "damos voltas juntos", ou seja, entramos em um consenso recursivo de informações que pode ser estabelecido em diferentes espaços educativos de convivência, como por exemplo, em um ambiente virtual de ensino e aprendizagem - AVEA (ROCHA, 2008). Por meio deste e mediados por um recurso tecnológico, é possível a relação entre o real aparente, visível, perceptível e o concreto, pensado na elaboração da compreensão do que está sendo vivido.

Isso significa dizer que é no diálogo com o outro que construímos as reflexões que nos levam ao desenvolvimento psico-intelectual necessário à formação profissional. Para Freire (1996) o diálogo é uma conduta necessária, na medida em que os seres humanos se transformam, cada vez mais, em seres humanos criticamente comunicativos. É um momento em que se encontram para refletir sua realidade, tal como a fazem e re-fazem. O diálogo é essencial na educação, seja ela presencial ou mediado por tecnologias em rede, e "somente o diálogo, que implica em pensar crítico, é capaz, também, de gerá-lo. Sem ele não há comunicação e sem esta não há verdadeira educação" (FREIRE, 1995, p. 96). Essa ideia é corroborada por Zitkoski (2008, p. 130) ao dizer que "o diálogo é a força que impulsiona o pensar crítico-problematizador em relação à condição humana no mundo".

Tradicionalmente as orientações das atividades de Estágios Supervisionados de Ensino são desenvolvidas exclusivamente de forma presencial, limitando os momentos de comunicação, ou seja da conversação. Isso ocorre por vários motivos entre eles pela falta de conhecimento das ferramentas tecnológicas-educacionais para mediar essas ações. Isso limita a interação orientador-estagiários, na universidade ao qual ele pertence $\mathrm{e}$, dessa forma, circunscreve também a possibilidade de contribuir para $\mathrm{o}$ desenvolvimento e atualização curricular das instituições escolares, de educação básica, que recebem os estudantes-estagiários.

Neste contexto, as ferramentas de colaboração via web, em ambientes de produção escolar colaborativa (como o wiki do Moodle), tornam-se um processo inovador e potencializador dos saberes necessários à prática docente. Em 2007, Tapscott \& Williams escreveram: "daqui a cinco anos, a capacidade de usar wikis será uma competência profissional exigida" (TAPSCOTT \& WILLIAMS, 2007, p. 308). Passado este tempo, percebemos que realmente as ferramentas de colaboração em ambientes 
virtuais, como o wiki do Moodle, no âmbito escolar, já se tornaram imprescindíveis para transformar o modo produtivo de estudantes e professores. Segundo Schons (2008, p. 89):

\begin{abstract}
os wikis, por se caracterizarem ferramentas voltadas, sobretudo para a colaboração de conteúdos, ganham dimensões importantes nas organizações no sentido de proverem suporte aos processos relacionados ao conhecimento. O seu uso promove a interação social, amplia a comunicação e estimula o potencial colaborativo, possibilitando que o fluxo de conhecimento seja potencializado através da conversão de conhecimentos tácitos e explícitos, fomentando a criação de novos conhecimentos.
\end{abstract}

Portanto, wikis incorporados em AVEA transformam-se em espaços para açãoreflexão-ação em rede ampliando espaços de conversação entre professores orientadores e estagiários. Com a mediação das atividades de orientações de estágio supervisionado de ensino com a ferramenta wiki, transformamos o campo de estágio de ensino em objeto de análise constante, potencializando investigações na e sobre a prática docente cotidiana. Assim, os momentos de reflexão possibilitam uma interpretação crítica das ações de estágio supervisionado, contribuindo de forma significativa para a formação do professor da educação profissional.

\title{
3. Especificidades metodológicas
}

Este trabalho, classificado como uma pesquisa qualitativa, contempla a analise de conteúdo dos planos de aula e sua implementação, em duas turmas de Estágio Supervisionado III, do Programa Especial de Graduação (PEG) de Formação de Professores para a Educação Profissional, na modalidade presencial. Este programa refere-se a uma proposta de formação pedagógica para os profissionais que atuam, ou pretendem atuar, como professores na Educação Profissional Técnica de Nível Médio, nas respectivas áreas de formação. Isto significa que os alunos ingressantes são oriundos de diversos cursos de formação, que compreendem sete eixos tecnológicos, entre eles Controle e Processos Industriais; Recursos Naturais; Produção Alimentícia; Gestão e Negócios; Informação e Comunicação; Ambiente, Saúde e Segurança; Infraestrutura. Por possuírem a formação técnica (de bacharéis), atualmente, em muitos casos, almejam e ou necessitam a formação pedagógica para lecionar nas suas respectivas áreas.

Constituído por três semestres, o PEG procura inserir o estudante na escola, desde o primeiro momento, especialmente, através dos Estágios Supervisionados I enfatizando a observação como objetivo central, correspondendo a 105 horas; Estágio Supervisionado II - detendo-se nos Planejamentos de Ensino (105 horas); e a docência orientada, no III, que corresponde a trinta (30), horas de aula, ministradas no último semestre da formação e sob a supervisão de dois orientadores: o professor regente da disciplina do curso técnico da escola concedente e o professor orientador da instituição proponente, no caso, a Universidade Federal de Santa Maria. Este, também com carga horária de 105 horas, constitui a última etapa das 315 horas exigidas pelo curso.

A tendência na formação de professores abordada - recortando o estágio curricular supervisionado, pressupõe articulação sistêmica, noções centrais de sujeito, de diálogo, de conhecimento. As dimensões teóricas e práticas pressupõem uma abordagem reflexiva, de natureza construtivista que, ao desafio de implementação de um currículo com tais características, impõe-se a necessidade de construção de um novo paradigma 
para o estágio curricular supervisionado, em que as tecnologias da informação e da comunicação perpassam a abrangência da formação pedagógica do futuro professor. $\mathrm{O}$ Curso, embora presencial, utiliza o Ambiente Moodle, como suporte para ensino e aprendizagem das disciplinas da grade curricular, procurando, no Estágio Supervisionado III, utilizar os recursos tecnológicos disponíveis, em especial a Wiki, que proporciona um importante processo de interação, necessário para a abordagem formativa, norteadora deste estudo de investigação.

O Wiki, constitui-se, portanto, em um recurso tecnológico-metodológico capaz de suportar as redes conversacionais que povoam um ambiente e o torna um espaço de ensino e aprendizagem, em que a construção do conhecimento se faz pela reflexão da ação, gerando, desta forma, mudanças de conduta, tanto pessoais como profissionais. Sendo assim, a proposta para os alunos estagiários baseia-se, entre outras coisas, na postagem dos planos de aula, através desta ferramenta. Antes de cada aula a ser ministrada, os estudantes devem postar o tema da aula, objetivo(s), metodologia, avaliação (se for o caso), bibliografia, enfim, um planejamento para o tempo da sua aula. O professor, por sua vez, deve orientar o aluno, sempre que necessário, visando a metodologia adequada, uso de recursos tecnológicos, didáticos. Posteriormente, o estagiário deve fazer uma análise da implementação, ou seja, um relato sobre como foi a execução do seu planejamento e, a partir, a reflexão da sua ação. Nesta, o alunoprofessor deve refletir sobre a sua atuação, abordando os pontos positivos, aspectos que podem ser melhorados e as contribuições cognitivas que a experiência lhe trouxe.

Os pesquisadores acreditam que esse é um dos momentos significativos da orientação, pois é neste escopo que ambos - professor e aluno - constituem uma rede de coordenações de ações num domínio de aceitação mútua. Esta rede de conversação emergiu na medida em que o grupo começou a se comunicar, a conversar, e o conversar, neste espaço, é realizado através de recursos capazes de dar suporte à comunicação, como o Wiki, correio eletrônico, fórum. O uso da ferramenta wiki, no ambiente virtual Moodle, proposto pelo planejamento da disciplina em foco, foi a hipótese de trabalho, estabelecida como tentativa de construção de um espaço efetivo para o registro autoral das reflexões realizadas, as produções sistematizadas, passando a ser também, o campo de observação e análise da categorização de indicadores para a supervisão de estágio e a prática pedagógica.

O processo das interações interindividuais foi constantemente alimentado pelos registros do professor orientador que, a cada planejamento de aula deixava suas contribuições na Wiki. A cada feedback, o professor escrevia refletindo sobre o processo percebido e fazendo as considerações pertinentes. O espaço de interação individual, ou seja, entre professor e aluno, tornou-se, aos poucos, povoado pelas reflexões registradas, em que foi possível mapear o processo individual acerca da relação teoria e prática, estendendo-se para uma maior abrangência. Ao final do semestre, os registros possibilitaram resgatar o processo de reflexão, as mudanças de conduta, tomada de decisões, construções conceituais, evidência de concepções de cada estagiário.

Para a organização deste trabalho optou pela configuração de uma atividade wiki no modo individual. O "modo wiki" determina se todo mundo pode editar a wiki (colaborativa), ou se cada um tem sua própria wiki a qual somente o estudante e o professor supervisor podem editar (individual). A opção pelo modo individual justifica- 
se pelo fato que cada estudante precisa fazer seus planejamentos e relatos das aulas implementadas, uma vez que o estágio supervisionado é uma atividade individual. Além disso, deixa o estudante mais à vontade para fazer suas análises e reflexões, pois, além dele, apenas o professor, que tem papel de orientar, tem acesso aos relatos. Isso permite que ele traga, inclusive, questões mais pessoais e até íntimas que influenciam na ação docente, para a reflexão com seu orientador.

Desta forma, a primeira fase dos apontamentos, como já mencionado, caracterizou-se pelas postagens do planejamento de cada aula, em que o aluno deveria expor, claramente, todos os momentos pedagógicos para desenvolver o conteúdo previsto. A fase posterior - o relato da implementação - compôs, juntamente, a estrutura, da rede de dados coletados para a pesquisa, possibilitando, assim, a análise através de seis categorias emergentes dos apontamentos realizados e com base nos estudos desenvolvidos por Bassani (2009). Portanto, identificamos as categorias: indagação (questionamentos/investigação); argumentação (chamar a discussão); reflexão (pensamento sobre a própria atuação). Estas, nortearam tanto os planos de Aula como os relatos da implementação, por parte da orientação e pelo aluno estagiário. Como cada orientador possuía um grupo de alunos (17 e 12) a análise abrangeu 29 unidades de registro, coletadas durante o primeiro semestre de 2012, Desta forma, a metodologia de pesquisa envolveu três momentos: análise do conteúdo das mensagens, através das categorias; agrupamento das análises e análise das contribuições das interações/reflexões, mediados pela ferramenta Wiki, para a formação do professor reflexivo, da Educação Profissional.

\section{Apresentação e Análises dos resultados}

Para analisar o conteúdo das mensagens, cada unidade de registro foi classificada de acordo com as categorias predominantes, ou seja, a partir das postagens, na ferramenta Wiki, foi feito uma análise detalhada de todos os Planos de Aula e Relatos de cada aluno, identificando as categorias emergentes, conforme os exemplos.

Exemplo de Plano de Aula:

O aluno postava o planejamento com antecedência de quinze dias a uma semana da data de implementação da aula. Os Planos de Aula seguiam metodologias variadas mas, em sua maioria estavam organizados em três Momentos Pedagógicos - MP (Abegg e De Bastos, 2005), visto que era um dos modelos trabalhados nas disciplinas do currículo do curso. Assim, após a postagem pelo aluno, o professor acessava a wiki e fazia suas orientações ao longo do texto em letras de cor diferente para melhor visualização das alterações/orientações. Cada professor tinha sua dinâmica, mas o professor da turma deste exemplo utilizava cores com significados diferentes (verde, quando estava tudo ok e o planejamento estava aprovado, amarelo, quando fazia observações que não, necessariamente, precisam ser contempladas e, em vermelho, quando o planejamento precisava ser modificado. No Plano de Aula deste exemplo, havia necessidade de alterações:

Data: $12 / 05 / 2012$

Tema: continuação do Sistema Cardiovascular $\quad$ (SCV)

Objetivos: Concluir o assunto iniciado na aula anterior com ênfase ao aprendizado das principais 


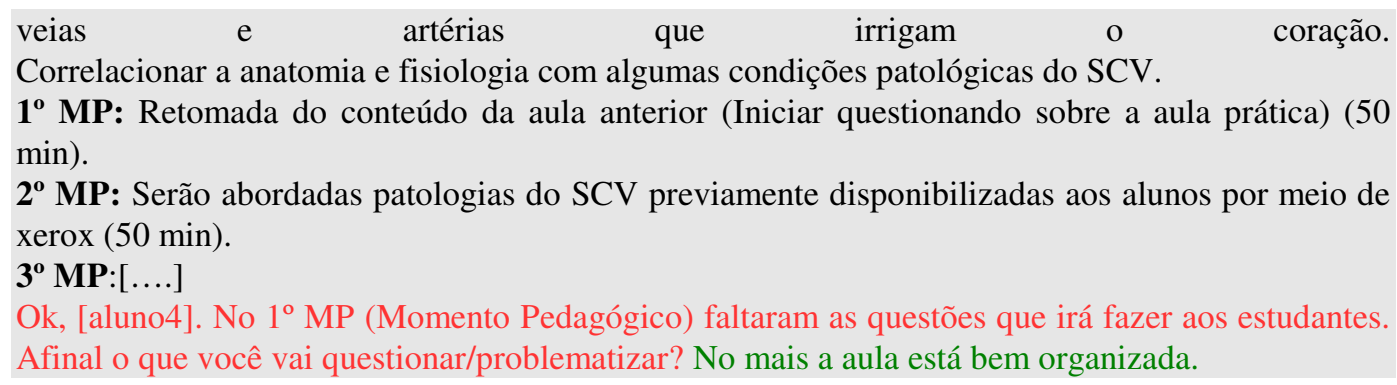

Após estas Indagações/orientações o aluno fez as alterações, modificando o planejamento e o $1^{\circ} \mathrm{MP}$ ficou assim:

$1^{\circ}$ MP: Retomada do conteúdo da aula anterior (Iniciar questionando sobre a aula prática): "Qual a diferença entre artérias e veias vistas na aula prática?" (Será explicado o conteúdo disponibilizado na apostila e através de uma atividade dinâmica com a participação dos alunos demonstrar como ocorre a pequena e a grande circulação (50 min.).

$2^{\circ}$ MP: [...]

Portanto, com estas alterações o estagiário pode fazer uma reflexão sobre os objetivos e quais os conteúdos que iria priorizar em sua próxima aula. Ao deixar o $\mathbf{1}^{\boldsymbol{}} \mathbf{M P}$ mais "completo" com informações mais claras sobre o que iria desenvolver na aula ele ficou também mais preparado, do ponto de vista da argumentação, para o diálogo com seus estudantes. Isso ficou demonstrado no relato da implementação no qual o estagiário destacou que o questionamento inicial foi essencial para o sucesso da aula. Este exemplo nos indica, portanto, a ocorrência das categorias Indagação, Argumentação, Reflexão.

\title{
Exemplo de Relato da Implementação:
}

\begin{abstract}
Data: 25/06/2012
Tema da Aula: Relações interpessoais no trabalho

Objetivos: Estudar sobre os fatores interpessoais e a qualidade de vida no trabalho; realizar uma dinâmica, visando a interação e comunicação entre o grupo

[...] Continuamos o conteúdo e em seguida o sinal para o intervalo tocou. Quando retornamos, continuamos a aula com as cadeiras em círculo. Gostei desta forma de organizar a sala, pois todos poderiam se olhar e interagir mais. Próximo ao término da aula utilizei uma estratégia nova em sala de aula. Pedi que os alunos pudessem escrever em no mínimo um parágrafo o que eles aprenderam daquela aula. A medida que eles foram entregando, fui lendo o que eles traziam. Era muito interessante, pois a aula foi a mesma para todos, no entanto, cada um trouxe um fragmento diferente daquela aula. Foi um feedback interessante para mim enquanto professora. Oi [Aluno 11], muito boa atividade. De acordo com o relato dos alunos, ela ajudou nas relações interpessoais?
\end{abstract}

Após esta reflexão e Indagação, o aluno fez as argumentações e novas reflexões:

Oi Profa. Segundo os alunos a dinâmica ajudou no entendimento do conteúdo. Mas honestamente, nesta dinâmica, senti que ajudou também para descontrair a turma. Os senti cansados (a grande maioria dos alunos trabalha de dia e estuda à noite, e certos dias, entendo que eles estejam mais cansados) e percebi que essa atividade os animou e os integrou ainda mais. Claro que cabe a mim enquanto professora sempre reforçar qual a intencionalidade em realizar tais dinâmicas, para que 
esta cumpra seus objetivos e para que os alunos possam percebê-las como uma forma de relacionar a teoria com a prática.

O exemplo desse relato indica a ocorrência das categorias Reflexão e Indagação, Argumentação, o que nos faz pensar na confirmação da ação-reflexão-ação. Assim, para o agrupamento das análises, cada unidade de registro foi classificada de acordo com as categorias predominantes, ou seja, a partir das postagens, na ferramenta Wiki, foi feito uma análise detalhada de todos os Planos de Aula e Relatos de cada aluno e identificado, em uma tabela (exemplo Tabela 01), a ocorrência de Indagações, Argumentações e Reflexões, tanto no P.A. (Plano de Aula), quanto no R.I. (relato da Implementação).

Tabela 01. Modelo para Análise dos Planos de Aula e Relatos das Implementações, através das categorias emergentes.

\begin{tabular}{|l|l|l|l|l|l|l|}
\hline Aluno & $\begin{array}{l}\text { P.A. } \\
\text { Indag. }\end{array}$ & $\begin{array}{l}\text { P.A. } \\
\text { Argum. }\end{array}$ & $\begin{array}{l}\text { P.A. } \\
\text { Refl. }\end{array}$ & $\begin{array}{l}\text { R.I. } \\
\text { Indag. }\end{array}$ & $\begin{array}{l}\text { R.I. } \\
\text { Argum. }\end{array}$ & $\begin{array}{l}\text { R.I. } \\
\text { Refl. }\end{array}$ \\
\hline 1 & $\mathrm{x}$ & & $\mathrm{x}$ & & $\mathrm{x}$ & $\mathrm{x}$ \\
\hline 2 & $\mathrm{x}$ & $\mathrm{x}$ & $\mathrm{x}$ & $\mathrm{x}$ & $\mathrm{x}$ & $\mathrm{x}$ \\
\hline Total & 02 & 01 & 02 & 01 & 02 & 02 \\
\hline
\end{tabular}

Como foram analisados dois casos (duas turmas), os resultados desta categorização apontam os seguintes resultados:

a) Turma A: 17 alunos (17 Wikis) analisadas: 10 indagações, 07 argumentações e 13 reflexões referentes aos Planos de Aula; 05 indagações, 11 argumentações e 16 reflexões referentes aos Relatos das Implementações dos Planos de Aula.

a) Turma B: 12 alunos (12 Wikis) analisadas: 07 indagações, 07 argumentações e 08 reflexões referentes aos Planos de Aula; 06 indagações, 06 argumentações e 11 reflexões referentes aos Relatos das Implementações dos Planos de Aula.

Podemos perceber, de acordo com os exemplos, que as mensagens não se enquadram apenas em uma categoria, ao contrário, se entrelaçam num ir e vir, que nos permite pensar na confirmação da reflexão sobre a ação de ambos os atores, na medida em que o "dar voltas juntos" abrange as indagações, que geram argumentações, que instigam reflexões, que, por sua vez, podem ou não serem aceitas, mas que convergem para um único objetivo: a formação de um professor reflexivo, a partir desta proposta de orientação. Portanto, a partir destas experiências, pudemos analisar as contribuições que a ferramenta Wiki pode proporcionar a ação-reflexão-ação em rede, pois as análises confirmam o "dar voltas", no entrelaçar do linguajar e do emocionar, transformando as próprias ações e corroborando, assim, com a formação do docente. 


\title{
5. Das conclusões temporárias
}

O propósito deste artigo foi problematizar uma vivência de estágio, em um programa de formação de professores para a educação profissional, utilizando as novas tecnologias como apoio a prática docente.

A luz dos conceitos de (inter)ação, reflexão sobre a reflexão na ação, aprendizagem, pudemos observar os registros, apontamentos, reflexões realizadas através da ferramenta Wiki, muitas vezes identificadas nos meandros subjetivos das conversas. Percebemos, a partir desta investigação, que as tecnologias educacionais em rede podem constituir-se importantes espaços de reflexão, que conduzem mudanças significativas na ação, ampliando ou restringindo as interações, de acordo com o posicionamento de cada ator. O registro dos Planos de aula e sua implementação, os feedbacks no espaço Wiki, por parte dos orientadores e estagiários, proporcionaram categorias de elementos indicadores para a orientação dos futuros estágios, na forma de rede de conversação, revelando, assim, a possibilidade de acompanhamentos, orientações e avaliações das aprendizagens e dos processos de reconstrução, resignificação da ação dos sujeitos aprendentes. Entre os pontos positivos destacou-se a construção de conhecimentos, uma vez que registrar, refletir, reavaliar levou ao amadurecimento do profissional docente. O tempo de estágio tornou-se efetivamente um período de construção de experiências, além do espaço acadêmico - desejo dos cursos de formação docente.

Observou-se o inicio de uma apropriação reflexiva, pelos futuros docentes, da necessidade e importância da inserção dos recursos disponíveis das tecnologias educacionais em rede, na proposta pedagógica, indo, portanto, ao encontro com as Diretrizes Curriculares Nacionais Vigentes. Apoiada pelos pressupostos da aprendizagem colaborativa, através de um ambiente virtual de ensino e aprendizagem, a proposta de orientação permite aos sujeitos aprendentes (professor e aluno) a autogeração, autoprodução do conhecimento.

\begin{abstract}
A autogeração é uma rede de processos de produção, nos quais a função de cada componente consiste em participar da produção ou da transformação de outros componentes da rede. Deste modo, toda a rede, continuamente, produz a si mesma. Ela é produzida pelos seus componentes e, por sua vez, produz esses componentes. Num sistema vivo, o produto de sua operação é a sua própria organização (CAPRA, 2006, p.89).
\end{abstract}

\section{Referencias}

ABEGG, I. e De Bastos, F. da P. Fundamentos para uma prática de ensino-investigativa em Ciências Naturais e suas tecnologias: Exemplar de uma experiência em séries iniciais. Revista Electrónica de Enseñanza de las Ciencias Vol. 4 Nº 3, 2005.

BASSANI, Patrícia B. Scherer. Trocas interindividuais no fórum de discussão: um estudo sobre as comunidades de aprendizagem em espaços de educação à distância. In: XVII Simpósio Brasileiro de Informática na Educação, 2006, Brasília. XX Simpósio Brasileiro de Informática na Educação, 2009.

MORIN, Edgar. Ciência com Consciência. Rio de Janeiro: Bertrand Brasil, 2005. 
ALARCÃO, Isabel. Escola Reflexiva e Supervisão. Porto: Porto Editora. 2000.

CAPRA, Fritjof. A Teia da Vida. São Paulo: Cultrix, 2006.

FREIRE, Paulo et al. Pedagogia: diálogo e conflito.. 4. ed. - São Paulo: Cortez, 1995.

FREIRE, Paulo. Pedagogia da Autonomia: saberes necessários à prática educativa. São Paulo: Editora Paz e Terra, 1996.

LIMA, Maria do Socorro Lucena. Redimensionando o Papel dos Profissionais da Educação: algumas considerações. In: Selma Garrido Pimenta, Evandro Ghedin (org) Professor reflexivo no Brasil: gênese e critica de um conceito. São Paulo: Cortez. 2002.

MATURANA, Humberto. A Ontologia da Realidade. Belo Horizonte: Ed. UFMG, 2002

PIMENTA, Selma G.; LIMA, Maria Socoro L. Estágio e Docência. 5.ed.São Paulo: Cortez, 2010.

RELA, Eliana; ROCHA, Karla Marques da; GOULART, Marceli Behm ; CARVALHO, Marie Jane Soares de . Estágio em Rede: a cooperação na prática docente. In: XVII Simpósio Brasileiro de Informática na Educação, 2006, Brasília. XVII Simpósio Brasileiro de Informática na Educação, 2006.

RESOLUÇÃO CNP/CP 1, de 18 de Fevereiro de 2002. Disponível em: $<$ http://portal.mec.gov.br/seesp/arquivos/pdf/res1_a.pdf> Acesso em 8 de outubro de 2006.

ROCHA, Karla Marques da . Estudo Sobre a Constituição de Um Sistema Social em Ambiente Virtual de Aprendizagem. Porto Alegre: UFRGS, 2008. Tese (Doutorado em Informática na Educação), Centro Interdisciplinar de Novas Tecnologias na Educação, 2008.

SCHÖN, D. Formar Professores como Profissionais Reflexivos. In: NÓVOA, A. (Org.). Os Professores e sua Formação. Lisboa: Dom Quixote, 1992.

SCHONS, Claudio Henrique (2008). A contribuição dos wikis como ferramentas de colaboração no suporte à gestão do conhecimento organizacional. Inf. \& Soc.:Est., João Pessoa, v.18, n.2, p. 79-91, maio/ago. 2008. Disponível em $<$ http://www.ies.ufpb.br/ojs2/index.php/ies/article/view/1706>. Acesso em: 04 de mai. de 2011.

SILVA, Marco. Interatividade: uma mudança fundamental do esquema clássico da comunicação. In: Compós: Encontro Nacional da Associação Nacional dos Programas de Pós-Graduação em Comunicação, 9, 2002, Porto Alegre: Anais. Porto Alegre: PUCRS, 2002. p.125-138.

TAPSCOTT, Don \& WILLIAMS, Anthony D.(2007). Wikinomics: como a colaboração em massa pode mudar o seu negócio. (Tradução de Marcello Lino). Rio de Janeiro: Nova Fronteira, 2007.

VIEIRA, Adriano. Humberto Maturana e o Espaço Relacional da Construção do Conhecimento. Educação e Humanidades. Brasília, v.1, n.2, p.1-6, nov. 2004. Disponível em: <http://www.humanitates.ucb.br/2/maturana.htm>. Acesso em: 03 de maio de 2012.

ZITKOSKI, Jaime José. Diálogo/Dialogicidade. In: STRECK, Danilo R.; REDIN, Euclides e ZITKOSKI, Jaime José (Orgs.). Dicionário Paulo Freire. Belo Horizonte: Autêntica Editora, 2008. 